\title{
Interaction Steel/Slag/Submerged Entry Nozzle and its Impact on Refractory Wear - Thermochemical Process Simulation
}

\author{
Harald HARMUTH ${ }^{1 / *}$ and Guangmin $\mathrm{XIA}^{2)}$ \\ 1) Ceramics, Department Mineral Resources Engineering, Montanuniversitaet Leoben, A-8700 Leoben, Austria. \\ 2) voestalpine Stahl GmbH, A-4020 Linz, Austria.
}

(Received on July 15, 2014; accepted on December 10, 2014)

\begin{abstract}
This work presents the generation and application of a process model which aims to increase the understanding of submerged entry nozzle (SEN) wear during continuous casting and its dependence on steel and slag compositions. An effective equilibrium reaction zone model was built and applied to calculate the equilibrium compositions of steel and slag at their common interface and in contact with the SEN. The results allow the estimation of the interface tension gradient responsible for Marangoni convection. Further, they include redox reactions at the slag/steel/refractory interface. Calculations were performed for a LC and a TRIP steel grade together with their respective mold fluxes. In both cases, the same SEN was used and the wear was assessed after service. In the case of the TRIP steel, the SEN showed by far lower wear and a less pronounced corrosion groove. The simulation showed that the interface tension difference responsible for Marangoni convection will be rather negligible for the case of TRIP steel, but it amounts to $150 \mathrm{mN} / \mathrm{m}$ for LC steel. Moreover, removal of carbon from the SEN zirconia-graphite sleeve will be caused by the reduction of silica in the slag. This is only possible at the three-phase boundary where the activity of the silicon formed is lowered by dissolution in the steel. Also, this effect is by far more distinct for LC steel and is in agreement with the different wear rate and corrosion groove. As a spin-off, the calculated interface tension might be interesting with respect to possible slag intrusion.
\end{abstract}

KEY WORDS: submerged entry nozzle; continuous casting; refractory wear; Marangoni convection; TRIP steel.

\section{Introduction}

A zirconia-graphite sleeve is typically used to protect submerged entry nozzles (SENs) from corrosion by mold slag during the continuous casting of steel. The higher stability is mainly due to the lower solubility of $\mathrm{ZrO}_{2}$ in the mold slag compared to that of the alumina component of the SEN body. Detailed investigations into the wear of SENs have been performed by previous researchers, with a few listed here. ${ }^{1-6)}$ It is well accepted that Marangoni convection intensifies the material wear and causes a distinct corrosion groove. The contribution of Marangoni convection to SEN wear was considered as early as $1982,{ }^{7)}$ and a more recent publication $^{8)}$ focused on the analytical calculation of mass transfer coefficients. The driving force in Marangoni convection is the interface tension gradient at the steel/slag boundary. As shown, for example, by Matsushita and coauthors, ${ }^{9)}$ mainly the steel oxygen content decreases the interface tension. This oxygen content is diminished close to the SEN surface as it reacts to $\mathrm{CO}$ with the carbon component of the refractory. The resulting increase in interface tension causes a fluid flow directed toward the refractory; this is superimposed on the flow of the upper convection roll (fre-

\footnotetext{
* Corresponding author: E-mail: harald.harmuth@unileoben.ac.at DOI: http://dx.doi.org/10.2355/isijinternational.55.775
}

quently observed during slab casting) that is in the same direction. What is the influence of the different steel and mold slag compositions on SEN wear? An earlier investigation performed post mortem studies of the same material after casting TRIP steel and LC steel together with the respective mold fluxes. ${ }^{6)}$ The SEN wear was much lower for TRIP steel, and there was a less-pronounced corrosion groove. The different shape of the corroded surface was observable, even though in both cases the SEN was lifted by approximately $100 \mathrm{~mm}$ during service in order to achieve more even wear. The chemical equilibrium at the threephase boundary slag/steel/SEN is important for assessing the wear conditions. A process model for the simulation of the reactions between the steel and mold slag was established and may be regarded as a step in this direction. ${ }^{10)} \mathrm{A}$ similar model could also include the SEN and allow the calculation of the equilibrium oxygen content in the steel at the steel/slag interface, both adjacent to the SEN and at some distance away from it. The tension gradient decisive for Marangoni convection follows from this calculation. Moreover, the interaction between the mold slag and the SEN can be calculated. The present work focuses on the generation and application of such a model. It should help to assess the interface tension gradient and possible Marangoni convection as well as reactions between SEN and slag that contribute to wear depending on the steel and slag compositions. Such a 
Table 1. Compositions of mold powders MP1, MP2 in carbon-free state represented in terms of oxides and $\mathrm{CaF}_{2}\left(\mathrm{mass}^{\circ}\right)$.

\begin{tabular}{cccccccccccccc}
\hline & $\mathrm{CaO}$ & $\mathrm{CaF}_{2}$ & $\mathrm{SiO}_{2}$ & $\mathrm{Al}_{2} \mathrm{O}_{3}$ & $\mathrm{MgO}$ & $\mathrm{Li}_{2} \mathrm{O}$ & $\mathrm{Na}_{2} \mathrm{O}$ & $\mathrm{K}_{2} \mathrm{O}$ & $\mathrm{TiO}_{2}$ & $\mathrm{FeO}$ & $\mathrm{MnO}$ & $\mathrm{B}_{2} \mathrm{O}_{3}$ & $\mathrm{P}_{2} \mathrm{O}_{3}$ \\
\hline $\mathrm{MP1}$ & 7.23 & 22.1 & 41.5 & 4.78 & 1.34 & 2.78 & 12.4 & 0.58 & 0.34 & 0.79 & 6.05 & 0.10 & 0.07 \\
$\mathrm{MP2}$ & 26.3 & 15.6 & 42.7 & 5.88 & 0.34 & 0.00 & 7.34 & 0.20 & 0.00 & 1.61 & 0.03 & 0.00 & 0.00 \\
\hline
\end{tabular}

model should therefore provide evidence of refractory wear and possible product improvements. The purpose would be to further increase the understanding of SEN wear.

\section{Procedure}

\subsection{Plant Data and Experimental Results Supporting the Process Model}

The developed and applied process model is based on plant data and experimental findings partly reported elsewhere, ${ }^{6,10)}$ therefore, only a brief description is provided. These findings show lower wear of the SEN during TRIP steel casting, and the present simulations were conducted to clarify this difference. However, the findings were adequate in providing the data necessary to establish and tune the process model. The zirconia-graphite sleeve of the SEN is composed of approximately $75 \%$ calcium-stabilized zirconia, $20 \%$ graphite, and $5 \% \mathrm{SiC}$ (compositions given here and in the following are in mass $\%) .{ }^{6}$ The lifetime of the SEN was 314 minutes in the case of TRIP steel, and only 95 minutes for LC steel. In both cases, approximately $7 \%$ of the zirconia-graphite sleeve was worn. The mold powder compositions are presented in Table 1, where MP1 designates TRIP steel and MP2 designates LC steel. The steel compositions are shown in Table 2 . A slab was cast with a mold cross section of $1360 \times 215 \mathrm{~mm}^{2}$; the slag pool thickness was approximately $10 \mathrm{~mm}$ and the casting speed was $0.018 \mathrm{~m} / \mathrm{s}$. The mold powder consumption was $0.013 \mathrm{~kg} / \mathrm{s}$. The next section provides the model parameters calculated from these data. Further, during the casting the MP1 slag specimens were sampled and their chemical composition was subsequently determined. This was performed until the steady state, which was of special interest as the process model intended to reveal the steady-state conditions of SEN wear. The steady-state contents (in mass $\%$ ) were $17.5 \% \quad \mathrm{SiO}_{2}$, $34.9 \% \mathrm{Al}_{2} \mathrm{O}_{3}$, and $1.6 \% \mathrm{MnO}$.

\subsection{Process Model}

A so-called effective equilibrium reaction zone model (EERZM) was applied for the simulations. This model is especially suitable for problems involving both the chemical reactions and the mass transfer between an interface and the bulk. While details on the EERZM modeling technique and its metallurgical applications can be found elsewhere, ${ }^{12)}$ sufficient background is provided here to explain the procedure and justify its validity. Two important assumptions have been made for the modeling procedure. It was presumed that mass transfer is limited by the diffusion in the Nernst boundary layers adjacent to the steel/slag interface. The mass transfer coefficients applied in the following Eqs. (1) and (2) represent the ratios of the effective diffusivities to the Nernst boundary layer thicknesses. Moreover it was assumed that the steel oxygen concentration at the interface determines the interface tension, so that it can be concluded
Table 2. Compositions of steel grades (mass $\%$ ).

\begin{tabular}{ccc}
\hline Steel grade & TRIP & LC \\
\hline $\mathrm{Al}$ & 1.0 & 0.042 \\
$\mathrm{Mn}$ & $>1.7$ & 0.215 \\
$\mathrm{Si}$ & 0.4 & 0.005 \\
$\mathrm{C}$ & 0.2 & 0.04 \\
Mold powder & MP1 & MP2 \\
\hline
\end{tabular}

from the oxygen concentration calculated from the process model.

For a single zone of the model representing a cell volume of homogeneous composition, e.g., the slag pool, the following differential equation follows from a balance of the mass flow:

$$
\frac{\partial}{\partial t}\left(V_{0} c_{0}^{(j)}\right)=-\beta \cdot A \cdot\left(c_{0}^{(j)}-c_{e}^{(j)}\right)+\dot{V} \cdot\left(c_{1}^{(j)}-c_{0}^{(j)}\right)
$$

Here, $V_{0}$ is the cell volume, $c_{0}^{(j)}$ is the concentration of the species $j$ in the bulk, and $c_{e}^{(j)}$ and $c_{1}^{(j)}$ are the species concentrations at the interface (subscript $e$ for equilibrium) and in the feed, respectively. Furthermore, $t$ is the elapsed time, $\beta$ is the mass transfer coefficient, $A$ is the steel/slag interface cross-sectional area, and $\dot{V}$ is the volume flux entering and leaving, respectively. Equation (1) shows that homogenization is assumed within the zone, and the concentration difference between the zone bulk and the interface is the driving force for mass transfer.

Applying the Euler method for the numerical solution of Eq. (1) results in the following difference equation:

$$
V_{0, i+1} c_{0, i+1}^{(j)}=\left(V_{0, i}-\Delta t \beta A-\Delta t \dot{V}\right) \cdot c_{0, i}^{(j)}+\Delta t \beta A c_{e, i}^{(j)}+\Delta t \dot{V} c_{1, i}^{(j)} \ldots
$$

In this equation, the additional subscript denotes the time step and $\Delta t$ is the time increment. Equation (2) represents the calculation procedure of EERZM: the second addend on the right side corresponds to the species mass in the effective equilibrium reaction zone (RZ), assuming that the concentration is expressed as mass per volume. Therefore, the $\mathrm{RZ}$ volume is equal to $\Delta t \beta A$ and thus it depends on the time step size. At any calculation step, the species mass in the RZ after equilibration is remixed with the species mass of a volume composed of the total zone volume, minus the $\mathrm{RZ}$ volume and the volume leaving within the time interval (first addend), plus the species mass entering over the time interval (third addend). Equation (2) represents the mixture calculation performed at every time step in EERZM, after the equilibrium was calculated. It further shows that each zone contains at least one reaction zone representing that part of its volume which is equilibrated within the time interval $\Delta t$. As Eq. (2) directly follows from Eq. (1), the concentration in the RZ equals the interface concentration if the 
$\mathrm{RZ}$ volume is properly chosen as identical to $\Delta t \beta A$. This is important for the research described here, as it shows that EERZM enables a calculation of the interface concentrations. These are relevant with respect to the interface tension. The result of EERZM is identical to the solution of the set of difference equations, Eq. (2). There is one for each species in each zone, coupled by the equilibrium calculations which further satisfy the mass balance.

For the case of TRIP steel, special attention must be paid to the structure of the model. In earlier work, ${ }^{10)}$ it was conceived that the steel flow in the upper convection roll has to be considered in order to quantitatively represent the reaction between mold slag and steel. The flow patterns were visualized by Thomas and coauthors. ${ }^{11)}$ It is essential that, during the stratified flow along the steel/slag interface, the reaction between both phases changes their composition, especially causing a depletion of aluminum in the case of TRIP steel. This is represented by the model schematically depicted in Fig. 1. Half the mold width is divided into four zones and associated RZs representing the slag/steel equilibrium and a fifth one that accounts for the equilibrium at the three-phase boundary slag/steel/SEN. As symbolized by the arrows in Fig. 1 the steel flow of the upper convection roll enters [Z1] and further passes through all other zones until it leaves [Z4]. All zones include the respective reaction zones shown in Fig. 1 as a part of their volume. Similarly, liquefied mold powder feeds the slag pool, which is represented by a single zone with five associated reaction zones (RZ1) - (RZ5). Liquid slag leaves the pool by entering the gap between mold and strand. The choice of the zone and reaction zone volumes is discussed later in this section.

This modeling approach is related to two previously published methods. ${ }^{10,13)}$ Both methods focus on the kinetics of the reactions between steel and slag and do not include the reaction with the SEN. One of them vertically divides the slag pool into several layers, each of them covering the entire cross section of the mold. ${ }^{13)}$ The other ${ }^{10)}$ uses a lateral division into four reaction zones per half mold width. While the former approach ${ }^{13)}$ is justified and promising for many applications, it was shown that the latter ${ }^{10)}$ may especially be necessary in the case of TRIP steel and accounts for the decrease in aluminum content during the stratified flow along the steel/slag interface. Therefore, this lateral division of the mold width into several zones is necessary to realistically model the steel oxygen content. For this reason, this approach was adopted here and extended by the reaction

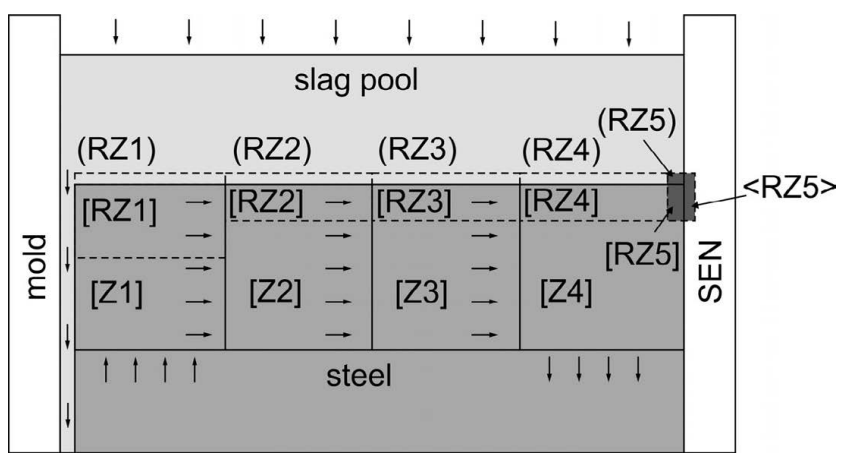

Fig. 1. Schematic representation of the effective equilibrium reaction zone model applied here; Zx..zone x, RZx..effective equilibrium reaction zone $\mathrm{x}$. zones representing the three-phase boundary steel/slag/SEN.

A further comment should be made with respect to the uniqueness of the model parameters. It has been shown ${ }^{10)}$ that an inverse identification procedure of the model parameters (mass transfer coefficients or RZ volumes, respectively) based on experimentally determined slag compositions dependent on the casting time gives an unambiguous result if only one zone is used for the slag pool and steel, respectively. Nevertheless, for the model applied here, the model parameters have been tuned to represent measured slag pool compositions, accurately especially for the steady state, for which influences on the SEN wear should be revealed. ${ }^{10)}$ The resulting mass transfer coefficients define the kinetics and the reaction cell volumes by the identities defined above. For the slag, the mass transfer coefficient was identified by $3.0 \cdot 10^{-5} \mathrm{~m} / \mathrm{s}$ for all zones, and for the steel, $1.2 \cdot 10^{-3}$ $\mathrm{m} / \mathrm{s}$ was received for the first zone and $0.6 \cdot 10^{-4} \mathrm{~m} / \mathrm{s}$ for all others. The high ratios of the mass transfer coefficients for the slag to those for the steel were reported previously. ${ }^{10)}$ The larger mass transfer for [Z1] in Fig. 1 is in accordance with the impact flow at that location. The time increment was chosen to be $1 \mathrm{~s}$. This is small enough to assure sufficient accuracy and a stable iteration.

For the symmetrical half of the mold represented by the model of Fig. 1, the following data have been used: the volume of the slag pool was $1.4 \cdot 10^{-3} \mathrm{~m}^{3}$, and the total volume of all steel zones accounted for $4.2 \cdot 10^{-4} \mathrm{~m}^{3}$. The relatively small quantity of the latter is in accordance with the stratified flow showing nearly no remixing, as seen from the simulations and measurements of Thomas et al. ${ }^{11)}$ The mass fluxes entering and leaving the cells are $6.6 \mathrm{~g}$ slag/s and 115 $\mathrm{g}$ steel/s. This means that a stable mass flow (input=output) was assumed. The interface area between each pair of adjacent steel/slag reaction zones was $0.035 \mathrm{~m}^{2}$. The commercial code FactSage ${ }^{\circledR}$ was applied for the equilibrium calculations, and a macro program was used to automate the simulation. While thermodynamic data are available for liquid steel and the interaction between components can be considered with high reliability, a database covering fluorine-containing mold slag compositions was recently developed by a research group at McGill University ${ }^{13)}$ and was applied here. All thermochemical calculations presented here were performed at a temperature of $1537^{\circ} \mathrm{C}$.

\section{Simulation Results}

Figures 2(a) and 2(b) show the equilibrium oxygen content $[\mathrm{O}]_{\mathrm{e}}$ in the steel at the phase boundary and the equilibrium oxygen activity $\mathrm{a}_{\{02\}}$ in the gas phase dependent on the RZ number for the cases of TRIP steel and LC steel, respectively. The figures show the results for the equilibrium at the steel/slag interface 20 minutes after the start of casting, which is close to the steady state. It can be seen that $[\mathrm{O}]_{\mathrm{e}}$ and $\mathrm{a}_{\{\mathrm{O} 2\}}$ show the same trend for LC steel, but not for TRIP steel. This is caused by the different aluminum contents. It is well known that the equilibrium oxygen content in $\mathrm{Fe}-\mathrm{Al}$ melts shows a minimum for a certain [Al] content. For the TRIP steel, the $[\mathrm{Al}]_{\mathrm{e}}$ content in [RZ1] is higher than that for the minimum; therefore, [RZ2] shows a lower $[\mathrm{Al}]_{\mathrm{e}}$ and $[\mathrm{O}]_{\mathrm{e}}$ content and the curve of $[\mathrm{O}]_{\mathrm{e}}$ in Fig. 2(a) starts with a negative trend. In contrast, due to the low [Al] content of the 


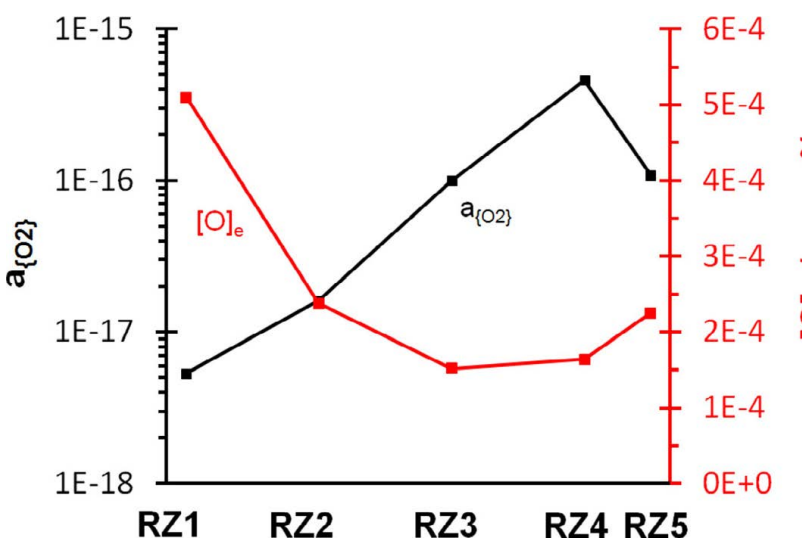

(a)

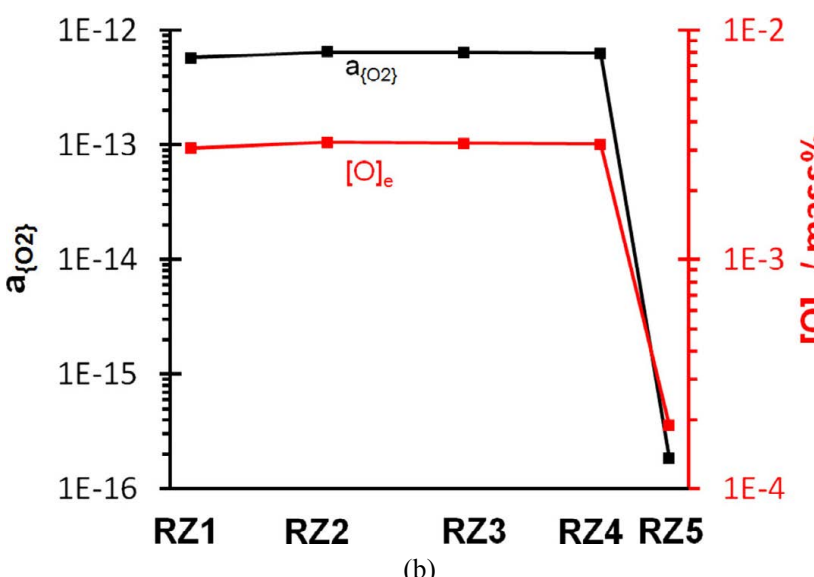

Fig. 2. Equilibrium oxygen content in the steel $[\mathrm{O}]_{\mathrm{e}}$ and equilibrium $\mathrm{O}_{2}$ activity in the gas phase $\mathrm{a}_{\{02}$ for (a) TRIP steel and (b) LC steel, dependent on the effective equilibrium reaction zone number 20 minutes after the start of casting. (Online version in color.)

LC steel, $[\mathrm{Al}]_{\mathrm{e}}$ is below the $[\mathrm{Al}]$ content of the minimum in all reaction zones, and shows only a minor variation between [RZ1] and [RZ4]. Therefore, in Fig. 2(b), [O]e is also nearly constant in the range [RZ1]-[RZ4], and it decreases for [RZ5] due to the equilibrium with solid carbon. The results show an essential difference between the two investigated steel grades with respect to Marangoni convection. While the difference in $[\mathrm{O}]_{\mathrm{e}}$ between $\mathrm{RZ4}$ and RZ5 is $3.00 \cdot 10^{-3}$ mass $\%$ for the case of LC steel, it is only $-6.11 \cdot 10^{-5}$ for TRIP steel. Therefore, it already may be assumed that Marangoni convection plays a role in the case of LC steel but not for TRIP steel. This will be discussed in more detail in the next section.

The reaction of the SEN carbon content with the silica of the slag is also of importance with respect to the SEN wear. Figure 3(a) shows the equilibrium contents of silica in the slag $\left(\mathrm{SiO}_{2}\right)_{\mathrm{e}}$ and silicon in the steel $[\mathrm{Si}]_{\mathrm{e}}$ at the steel/slag interface for reaction zones RZ4 and RZ5 in the case of TRIP steel. The abscissa shows the slag pool silica content, which is also represented as the dashed curve in the diagram. The silica content depicted on the abscissa refers to the time between one minute (largest value) and 20 minutes (smallest value) after the start of the casting. It can clearly be seen that $\left(\mathrm{SiO}_{2}\right)_{\mathrm{e}}$ is smaller in (RZ5) compared to (RZ4). Further, with increasing elapsed time of the casting process, the slag pool silica content represented on the abscissa of

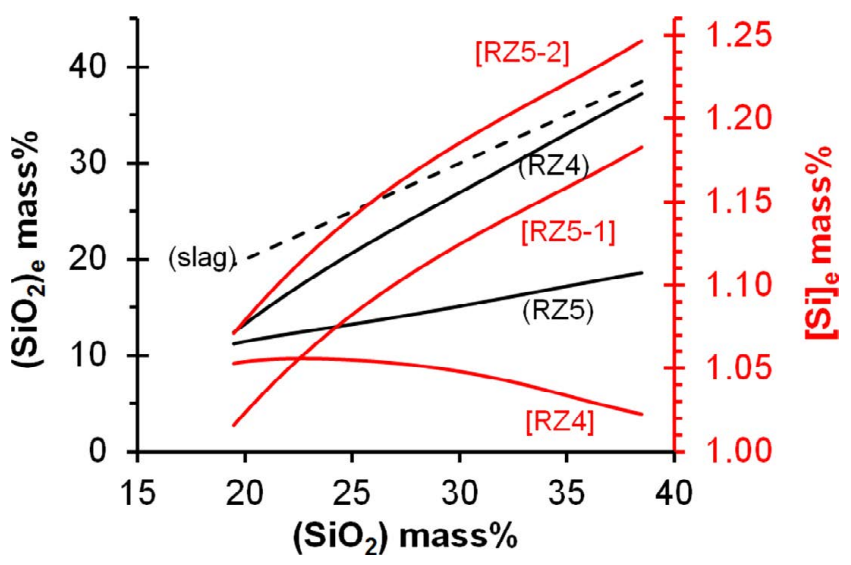

(a)

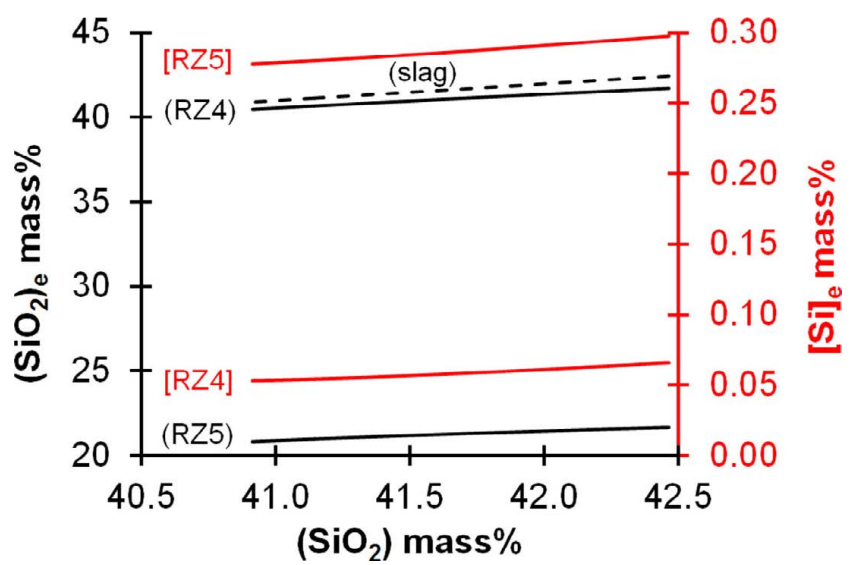

(b)

Fig. 3. Equilibrium silica content in the slag and silicon content in the steel for effective equilibrium reaction zones RZ4 and RZ5 in dependence of the slag pool silica content as calculated for (a) TRIP steel and (b) LC steel. Note that the round brackets are for slag silica content (left ordinate) and the square brackets are for steel silicon content (right ordinate). (Online version in color.)

Fig. 3(a) monotonously declines, and the difference of the equilibrium silica content in (RZ5) and (RZ4) decreases. This difference is due to a reduction of $\left(\mathrm{SiO}_{2}\right)$ by the SEN graphite content. Products of this redox reaction are $\mathrm{CO}$ and elementary silicon. Progress of this reaction necessitates a relatively low activity of the reaction products. While the activity of $\mathrm{CO}$ is decreased by mixing with the atmosphere, that of silicon is reduced only at the three phase boundary by dissolution into the steel. Therefore reduction of $\left(\mathrm{SiO}_{2}\right)$ takes place at the three-phase boundary slag/steel/SEN only. So the mold flux silica content acts as the oxygen carrier causing oxidation and loss of carbon, including the carbon bond of the SEN. This is very relevant for wear as erosion will be enhanced by the loss of the bond.

The further reduction of the slag pool silica content by the solid carbon is due to the fact that the [Al] content and the associated activity are already rather low in [Z4]. To give an example, 20 minutes after the start of casting, the [Al] content in [Z4] is 0.107 mass $\%$, which is almost a power of ten lower than the initial one. At earlier times, it is of course even lower, e.g., 0.038 mass $\%$ after one minute, because the slag pool silica content is higher and more aluminum is consumed in [RZ1]-[RZ3]. In addition, a thermochemical calculation showed that the silica reduction does not take 
place at the slag/SEN two-phase boundary, where a decrease in silicon activity by liquid steel is missing. Moreover, Fig. 3(a) shows the [Si] e content for [RZ4] and [RZ5]. Two curves are shown for [RZ5]. The curve showing the [Si $]_{\mathrm{e}}$ content as calculated by the process simulation is denoted as [RZ5-1]. An unexpected result is that it cuts the curve for [RZ4]. The reader might expect a higher silicon content in [RZ5] as there elementary silicon is dissolved after the reduction process quoted above. Nevertheless, also carbon from the SEN graphite is dissolved into the steel of [RZ5]. This additional carbon input decreases the rise of the silica percentage in [RZ5] compared to [RZ4]. For a low slag pool silica content and a therefore minor amount of silica reduced and dissolved into the steel it even causes a decrease of [Si] in [RZ5] compared to [RZ4]. To show this clearly, in the final simulation result for [RZ5] the carbon content was canceled and the residue balanced to $100 \%$ again. The outcome is represented by the curve [RZ5-2], which lies above [RZ4] as expected. The difference in [Si] $]_{\mathrm{e}}$ between [RZ5] and [RZ4] is the driving force for diffusion acting to decrease [Si $]_{\mathrm{e}}$ in [RZ5], thus supporting carbon oxidation. From Fig. $3(\mathrm{a})$, it can be seen that the difference between both contents $\left(\mathrm{SiO}_{2}\right)_{\mathrm{e}}$ and $[\mathrm{Si}]_{\mathrm{e}}$ in reaction zones 4 and 5 are decreasing with increasing casting time (decreasing slag pool silica content) and are negligible when the steady state is approached. A different situation is seen for LC steel in Fig. 3(b). Here, only a minor decrease in the slag pool silica content is observed. The differences of the $\left(\mathrm{SiO}_{2}\right)_{\mathrm{e}}$ and $[\mathrm{Si}]_{\mathrm{e}}$ contents in reaction zones 4 and 5 nearly do not change with time, and the difference in the $\left(\mathrm{SiO}_{2}\right)_{\mathrm{e}}$ content is similar to that of Fig. 3(a) after one minute. From this, it follows that carbon oxidation will be by far more severe in the case of LC steel, followed by more intense erosion.

\section{Discussion of Results}

One major issue is the estimation of the interface tension based on the equilibrium oxygen content. Numerous investigations deal with the dependence of surface and interface tension on the oxygen content; some of these results are provided here. ${ }^{9,14-16)}$ It was observed that, for a given oxygen content, different mold slag compositions have only a minor effect on the interface tension. ${ }^{9,16)}$ The aluminum content is of interest in the case of the TRIP steel investigated here. Sun ${ }^{15)}$ observed only a slight increase in interface tension, which appears to not be relevant for the contents considered here. To assess possible Marangoni convection, the difference in interface tension $\Delta \sigma$ between RZ 4 and 5 is of interest. To give a numerical example, in their work on the influence of Marangoni convection on refractory wear, Pötschke and Brüggmann ${ }^{8)}$ calculated a value of $\Delta \sigma=140$ $\mathrm{mN} / \mathrm{m}$ based on a formula of Borgmann. ${ }^{14)}$ From a more recent work of Park et al. ${ }^{16)}$ a value of $94 \mathrm{mN} / \mathrm{m}$ would follow for the same example. It is clear that the formula of Borgmann ${ }^{14)}$ overestimates $\sigma$ for low oxygen content, as it contains the logarithm of the oxygen content as a subtrahend. In contrast, the equation provided by Park et al. ${ }^{16)}$ is based on the Gibbs isotherm for adsorption and relates the interface tension to the oxygen activity. Therefore, the latter work $^{16)}$ is used here to calculate $\Delta \sigma$ from the simulation results. For the case of LC steel, it yields $\Delta \sigma=150 \mathrm{mN} / \mathrm{m} 20$

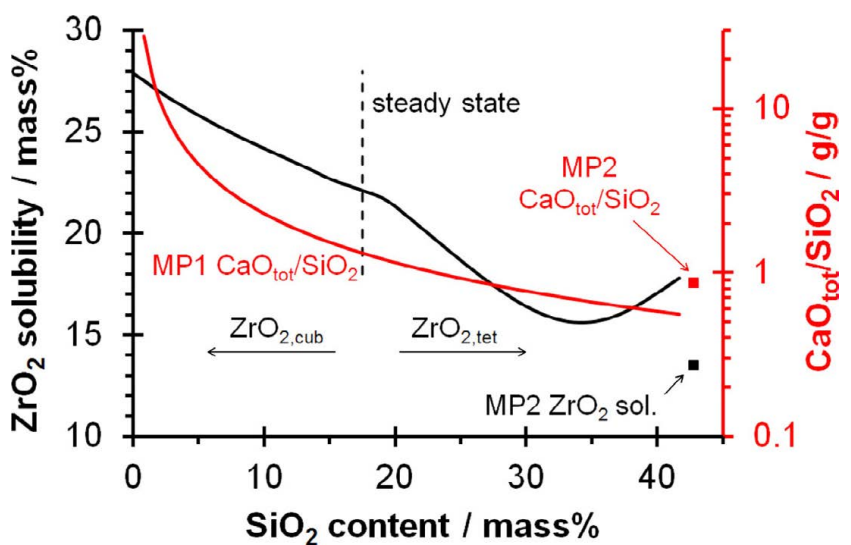

Fig. 4. Zirconia solubility and lime-to-silica ratio for MP1 and MP2; the abscissa shows the mold flux silica content. (Online version in color.)

minutes after the start of casting, and it depends only slightly on time. This is even more than the example quoted above. ${ }^{8)}$ For the case of TRIP steel, a value of $\Delta \sigma=-4 \mathrm{mN} / \mathrm{m}$ results 20 minutes after the start of casting. Out of this, practically no Marangoni convection develops for the case of TRIP steel. It should be noted that the composition of the LC steel considered here is still not the worst case. A decrease in [Mn] content will tend to further increase $\Delta \sigma$ and Marangoni convection; the simulation procedure presented here may be applied to assess such conditions.

Further, zirconia solubility in both mold fluxes should be considered. Figure 4 shows the dependency on the slag pool silica content for MP1. While a steady state is achieved under the service conditions as indicated in the figure, the calculation is further pursued for theoretically the total silica reduction. It can be clearly seen that the zirconia solubility is always by far higher for the case of MP1, but with respect to SEN wear this effect is overruled by the other influences quoted above. Figure 4 also shows the $\mathrm{CaO}_{\text {tot }} / \mathrm{SiO}_{2}$ mass ratio, which includes the total $\mathrm{Ca}$ content (including $\mathrm{CaF}_{2}$ ) expressed as $\mathrm{CaO}$. After a slight decrease, the zirconia solubility is raised by an increase of this ratio with progressing silica reduction. Tetragonal zirconia is stable until a steady state is achieved. In the case of calcium-stabilized cubic zirconia, therefore, $\mathrm{CaO}$ is dissolved out of the solid solution by the slag. This has also been observed in post mortem investigations. ${ }^{6)}$ As a result, destabilization and disintegration of zirconia occurs and decreases the erosion resistance of the material.

A further possible wear factor should be mentioned. In an early work, Hauck and Pötschke ${ }^{7)}$ revealed the contribution of carbon dissolution in the slag to SEN wear from experimental investigations. This may well be the case here. One can imagine that carbon oxidation by simultaneous silica reduction occurs at the three-phase boundary only, where silicon can be simultaneously dissolved in the steel melt thus lowering silicon activity. Above this line (and still within the corrosion groove), carbon dissolution in the slag might contribute to carbon removal. Nevertheless, this process is not further considered here, as a specific dependence on the steel grades in this study is not evident. 


\section{Conclusions}

The simulations presented here reveal the following reasons for the lower wear and the more even corrosion groove in the case of TRIP steel. Even though the aluminum content of the steel decreases during the stratified flow from the mold wall to the SEN, it is still high enough to significantly decrease the oxygen content. This yields an only marginal gradient of the interface tension close to the SEN surface. Marangoni convection practically drops out; therefore, the mass transfer of all processes contributing to wear is by far lower compared to the case of LC steel. One of them is silica reduction associated with carbon oxidation at the threephase boundary steel/slag/SEN. In the case of TRIP steel, this is not only hindered by the minor mass transfer, but it is also decreased by the lower slag silica content. Other processes less pronounced without Marangoni convection may be zirconia and carbon dissolution in the slag and possibly carbon dissolution in the steel. The simulation procedure may therefore be applied to assess possible SEN wear and its dependence on steel grade and slag composition.

\section{Acknowledgment}

Inspiring scientific contacts with In-Ho Jung/McGill University and his research team are gratefully acknowledged. Investigations were funded by K1-MET competence center. The research program of the competence center "Advanced Metallurgical and Environmental Process Development" (K1-MET) is supported within the Austrian program for competence centers COMET (Competence Center for Excellent Technologies) with funds from the Federal Ministry for Transport, Innovation and Technology, the Federal Ministry of Economy, the province of Upper Austria and Styria, the Styrian Business Promotion Agency, of the Tyrol, and the Tyrolian Future Foundation.

\section{REFERENCES}

1) K. Mukai, J. M. Toguri, N. M. Stubina and J. Yoshitomi: ISIJ Int., 29 (1989), 469.

2) E.-P. Heikkinen, R. A. Mattila, T. M. T. Kokkonen and J. J. Härkki: Proc. 85th Steelmaking Conf., Nashville, ISS, Warrendale, (2002), 419.

3) E. Brandaleze and C. Gorosurreta: Proc. 14th IAS Steelmaking Conf., Instituto Argentina de Siderurgica, Buenos Aires, (2003), 629.

4) Y. Aiba, K. Oki, M. Sugie, K. Kurihara and S. Oya: Taikabutsu Overseas, 5 (1985), 3.

5) Y. M. Lee and H. Yin: Advances in Refractories V, 49th Annual Conf. of Metallurgists (COM), 5th Int. Symp., The Michel Rigaud Symp., CIM Canadian Institute of Mining, Metallurgy and Petroleum, Westmount, (2010), 221.

6) H. Harmuth, N. Kölbl, B. Rollinger and G. Xia: Proc. 6th Int. Symp. on Reftractories, Zhengzhou University Press, Zhengzhou, (2012), 477.

7) F. Hauck and J. Pötschke: Arch. Eisenhüttenwes., 53 (1982), 133.

8) J. Pötschke and Ch. Brüggmann: Steel Res. Int., 83 (2012), 637.

9) T. Matsushita, T. Watanabe, M. Hayashi and K. Mukai: Int. Mater. Rev., 56 (2011), 287.

10) H. Harmuth and G. Xia: Proc. 8th European Continuous Casting Conf. (ECCC), The Austrian Society for Metallurgy and Materials, Leoben, Austria, (2014).

11) B. G. Thomas, Q. Yuan, S. Sivaramakrishnan and S. P. Vanka: JOMe, http://www.tms.org/pubs/journals/JOM/0201/Thomas/Thomas-0201. html, (accessed 2014-07-02)

12) M.-A. Van Ende, Y.-M. Kim, M.-K. Cho, J. Choi and I.-H. Jung: Metall. Mater. Trans. B, 42 (2011), 477.

13) I.-H. Jung and M.-A. Van Ende: Proc. 8th Eur. Continuous Casting Conf. (8th ECCC), The Austrian Society for Metallurgy and Materials, Leoben, Austria, (2014).

14) F.-O. Borgmann: PhD Thesis, Technical University of Berlin, (1971), 10 .

15) H. Sun: Proc. 3rd Int. Cong. on the Science and Technology of Steelmaking (ICS), Association for Iron and Steel (AIST), Warrendale, PA, (2005), 45.

16) S. C. Park, H. Gaye and H. G. Lee: Ironmaking Steelmaking, 36 (2009), 3 . 